\title{
PSICOPATIA NO DIREITO PENAL: RESPONSABILIDADE DO PSICOPATA NO SISTEMA JURIDICO BRASILEIRO.
}

\author{
Gabriel Felipe Rodrigues Damaceno \\ Universidade do Oeste Paulista - UNOESTE, Curso de Direito, Presidente Prudente, SP. E-mail: \\ gdamaceno99@yahoo.com.br
}

\begin{abstract}
RESUMO
O elencado trabalho apresentado tem como objetivo principal estudar a figura do psicopata dentro da sociedade em que o mesmo habitará, procurando de forma complexa e detalhada sistematizar suas atitudes, tendo o escopo de definir suas responsabilidades perante seus atos criminosos. Assim, é forçoso a compreensão do entendimento do Direito Penal Brasileiro em caso de crimes cometidos pelos psicopatas. O início da pesquisa se dá com a explanação do entendimento do conceito de psicopatia, elencando alguns casos de psicopatas já existentes, sendo seguido pelos estudos da criminologia (teoria do crime), focando especialmente à culpabilidade e responsabilidade para melhor compreensão do tema.
\end{abstract}

Palavras-chave: Psicopatia. Direito Penal. Psicopata. Culpabilidade. Responsabilidade.

\section{PSYCHOPATHY IN CRIMINAL LAW: RESPONSIBILITY OF THE PSYCHOPATH IN THE BRAZILIAN LEGAL SYSTEM.}

\begin{abstract}
The listed work presented aims to study the psychopath in the society where he lives, looking in a complex and detailed way to systematize their attitudes, having the scope to define their responsibilities for their criminal acts. Thus, it is necessary to emphasize the understanding of Brazilian Criminal Law in cases of crimes committed by psychopaths. The research begins with the explanation of the concept of understanding psychopathy, listing some cases of existing psychopaths, being followed by the studies of criminology (crime theory), focusing especially on guilt and responsibility for a better understanding of the subject. .
\end{abstract}

Keywords: Psychopathy. Criminal Law. Psycho. Guilt. Responsibility. 


\section{INTRODUÇÃO}

Ao se referir a palavra psicopatia, logo nos remete ao agente o qual possui em seu âmago um caráter cruel, rebelde e agressivo, porém, tal pensamento por muitas das vezes é direcionado de forma equivocada, pois, nem sempre os psicopatas serão ou terão tais instintos.

Para a medicina psiquiátrica, o tema em tela pode ser entendido como uma desordem de personalidade, possuindo principais característica como: a) falta de empatia; b) deslealdade; c) ausência de sentimentos (remorso, felicidade...). Possuindo um artifício, que por meio destes os levará a mentir de maneira natural e pela mentira podem e conseguem manipular várias pessoas afim de almejar seus objetivos.

Ao abordar o assunto da psicopatia percebe-se que o tema não recebe a relevância que deveria, tendo em consideração que, uma vez inserido em liberdade na sociedade, o agente pode voltar a cometer os mesmos crimes. Assim, por meio deste trabalho será explanado e apresentado a figura do psicopata e desmistificá-la, de tal forma e incorporá-la no campo jurídico do nosso país.

Compreender suas motivações ao qual o leva à delinquir, observando características de sua personalidade e o ambiente sócio cultural em que está inserido, é de suma relevância para a aplicação da lei penal. Deste modo, a psicologia forense, juntamente com a criminologia, geraram conceitos e trouxe informações relevantes tanto para o ramo da psicopatia como para o Direito em si. E é neste diapasão surge o psicopata, tendo como base a psicopatia que no qual vem a ser o tema principal do estudo aqui presente.

\section{METODOLOGIA}

Referido estudo será construído através de pesquisas complexas em bibliografias, doutrinas e leis sobre tal tema em questão, ainda para afim de maior compreensão, entrevistas com profissionais da área (psicologia) para aprofundar a tese e conhecer novas teorias. Sempre acompanhado de um orientador o qual direcionou para melhor entendimento

\section{DO PSICOPATA}

Para começarmos a tratar sobre o tema, podemos tentar entender, ou menos suscitar uma breve introdução sobre o fato de onde viria ou teria acontecido tais tipos infames de crimes primordialmente. Podemos então assim perceber que desde dos tempos bíblicos a aparência do psicopata já é explicita, como por exemplo em GENESIS, quando diz que CAIM sem sentimento nenhum mata seu irmão $A B E L$, tal passagem sendo conhecida pelos doutrinadores como crime original.

Surgiu-se então "os criminosos" e junto a ele a conduta criminosa (criminologia), que para melhor compreensão é dita por Nestor Sampaio Pentado Filho (2012 pg17) como: " a ciência empírica (baseada na observação e na experiência) e interdisciplinar que tem por objetivo de análise o crime, a personalidade do autor do comportamento delitivo, da vítima e o controle social das condutas criminosas".

Ainda neste mesmo diapasão ele mesmo complementa que:

a criminologia é uma ciência do "ser", empírica, na média em que o seu objeto (crime, criminoso, vitima e controle social) é visível no mundo real e não no mundo dos valores, como ocorre com o direito, que é uma ciência "dever-ser", portando normativa e valorativa". (Penteado filho, 2012 pg 170),

Para melhor ser compreendido, pode ainda ser exemplificado que a criminologia não possui conceito formalmente concreto e definido, pois poderá e é definido de variadas formas por diversos autores que tratam sobre o tema, como por exemplo:

- Edwin H. Sutherland: "Criminologia é um conjunto de conhecimentos que estudam o fenômeno e as causas da criminalidade, a personalidade do delinquente, sua conduta delituosa e a maneira de ressocializá-lo". 
Nelson Hungria: "Criminologia é o estudo experimental do fenômeno crime, para pesquisar-lhe a etiologia e tentar a sua debelação por meios preventivos ou curativos".

E por fim, segundo Sergio Salomão (Criminologia pag 31) nos ensina:

criminologia é um nome genérico designado a um grupo de temas estreitamente ligados: o estudo e a explicação da infração legal; os meios formais e informais de que a sociedade se utiliza para lidar com o crime e com atos desviantes; a natureza das posturas com que as vitimas desses crimes serão atendidas pela sociedade; e por derradeiro, o enfoque sobre o autor desses fatos desviantes.

\section{PSICOPATIA - CONCEITOS}

Primeiramente, deve -se entender que psicopata não pode ser considerado como louco, pois assim seria uma doença mental. Pelo ponto de vista médico, a psicopatia não se enquadraria em tais requisitos (doente mental) e sim um transtorno personalidade. O Manual de diagnóstico e estatística das perturbações mentais, enquadrou-a como transtorno de personalidade antissocial, "o transtorno refere-se a um conjunto de comportamentos criminosos e antissociais, enquanto que a psicopatia seria definida como um conjunto de traços de personalidade além dos comportamentos sociais." (Roberto D.Here 2013 pag 40-41).

Logo, para ele ambos institutos possuem para si características diferentes. Em síntese, os psicopatas não conseguem criar relações verdadeiras de afeto e de amor, por isso conclui-se que ele possui um defect da emoção, entretanto o psicopata ele possui um sistema cognitivo perfeito (intacto).

Sendo assim, fato é de ser exposto que os mesmos psicopatas não são completamente normais, pois acarretam para si um problema neurobiológico que afeta sua personalidade introduzindo em seu caráter (seu modo de agir) perante a sociedade, tento como meios motivadores para gerar tal consequência abusos sofridos durante a infância.

Neste diapasão, podemos suscitar o famoso caso de Beth Thomas a menina psicopata, história verídica de uma menina que perdeu sua mãe quando possuía apenas um ano de idade, ficando assim junto de seu irmão sob tutela do pai biológico, o qual abusou sexualmente da mesma, o que gerou grande impacto para a menina transformando-se em um mente psicopata, levando-a possuir uma personalidade agressiva, onde por diversas vezes tentou matar a seu irmão mais novo.

Pode ficar definido assim, que a ausência de sentimento sempre será integrada ao psicopata, e partir desse pensamento foi que surgiu a expressão "daltismo moral", sendo qualificado como aqueles sem capacidade de compreensão do certo ou errado. Sendo assim, é importante mencionar o entendimento do criador desta tese, Manuel Cancio Meliá, onde em suas palavras expressa:

esses indivíduos não apresentam freios inibitórios quanto à realização de comportamentos desvalorizados socialmente. Assim, não se trata de sujeitos incapazes de compreender o certo ou errado, ou que não possam controlar suas ações, mas sim, indiferentes emocionais.

O mesmo assunto "daltonismo moral" é exposto pelo pesquisador Robert D. Hare que de forma resumida afirma que da mesma forma que as pessoas que não enxergam as cores, falta ao psicopata um elemento importante da experiência, qual seja, o aspecto emocional.

Pode-se dizer que psicopata no amago de sua frieza machucaria animais ou pessoas sem motivação alguma, somente afim de seu deleite: "Essa seria a frieza dele, o não reconhecimento da humanidade no outro e até mesmo o não reconhecimento de sua própria humanidade (COSTA, 2014, pag 14).

Cleckley, foi uns dos primeiros estudiosos sobre o tema, em seu livro "the mask of insanity", elencou 16 características que podem ser encontradas em um psicopata : A) charme e boa inteligência; b) ausência de delírio (por isso não se confunde com doente mental); c) 
ausência de nervosismo; d)não confiável; e) falsidade; f) ausência de remorso e vergonha; g) anti social; h) julgamento deficiário; i) incapacidade de amar; j) não possui reações afetivas; k) perda especifica insight; I) falta de resposta $\mathrm{m}$ ) desagradável $\mathrm{n}$ ) suicídio raramente concretizado; o) vida sexual e interpessoal trivial p) fracasso em seguir plano de vida. Destacando, que o rol supra citado foi de grande ajuda para qualificar um psicopata e na busca de suas naturezas.

\section{DA CULPABILIDADE E DA RESPONSABILIDADE}

A culpabilidade de modo geral pode ser entendida como juízo de reprovação pessoal, que por sua vez será analisada a conduta típica e ilícita ao qual tenha das praticada pela pessoa/agente.

Assim, para (Luiz Regis Prado, 2007, pag 408):

a culpabilidade é a reprovabilidade pessoal pela realização de uma ação ou omissão típica e ilícita. Assim não há culpabilidade sem tipicidade e ilicitude, embora possa existir ação típica e ilícita inculpável. Devem ser levados em consideração, além de todos os elementos objetivos e subjetivos da conduta típica e ilícita realizada, também, suas circunstancias e aspectos relativos à autoria.

Sobre o exposto tema: " hordinariamente, a culpabilidade é vista como possibilidade de reprovar o autor de um fato punível porque, de acordo com os fatos concretos, podia e devia agir de modo diferente. Sem culpabilidade não haver pena e sem dolo ou culpa não pode existir" (Cesar Roberto Bitencourt 2000,pag 125).

E ainda em sua obra complementa (BItencourt 2003, pg 14):

A culpabilidade, como fundamento da pena, refere-se ao fato de ser Possível ou não a aplicação de ua pena de uma série de requisitos - capacidade de culpabilidade, consciência de ilicitude e exigibilidade da conduta - que constituem os elementos positivos específicos do conceito dogmático de culpabilidade. A ausência de qualquer desses elementos positivos para impedir a aplicação de uma sanção penal.

Logo, podemos concluir que tal elemento por diversos momentos possui um condão diferenciado por alguns e outros estudiosos, mas em linhas gerais se mentem que será culpável aquele que possui uma conduta tipificada com ilícita, por meio de uma reprovação constante (ou naquele momento) da sociedade em que o agente ali se mantem.

Ronaldo Tanus Madeira, entende que se um doente mental comete-se algum delito, não poderia o mesmo responder, pois não agiu com dolo ou culpa, pois sua capacidade mental não o deixa entender sobre o ilícito ali recorrente, assim não possui maneiras psíquicas de distinção do certo e do errado, desta maneira observa-se que sem a imputabilidade não se faz a relação subjetiva da conduta e resultado. Nas palavras de Liszt a imputabilidade é: "aquele estado psíquico do autor que the garante a possibilidade de conduzir-se socialmente" .Já segundo Shiela Beirrenbach, diz que a culpabilidade se dá ao finalismo, (juízo de reprovação).

\section{DA IMPUTABILIDADE E INIMPUTABILIDADE:}

Para que o agente possa ser responsabilizado penalmente pelo fato típico e ilícito que cometeu é preciso que seja imputável. A imputabilidade é assim descrita como a possibilidade de se atribuir, impedir o fato típico e ilícito ao agente, sendo a imputabilidade regra e inimputabilidade como exceção.

Assim, podemos entender que tal instituto tem como uma das funções se direcionar para a saúde mental e psíquica do agente, ou seja, será elencado quem possui condições e capacidade de praticar crimes com pleno discernimento, ou seja a imputabilidade aqui exposta será para verificar se o agente poderá ou não sofre sanções penais, sendo que somente poderá aplicar a pena a quem ao tempo do delito possui-se compreensão físicas e psicológica sobre o fato. Neste 
raciocínio, o agente deve ter totais condições de controle sobre sua vontade. Em outras palavras, imputável é não apenas aquele que tem capacidade de intelecção sobre o significado de sua conduta, mas também de comando da própria vontade.

Da mesma forma defende Damásio de Jesus (2000)

imputar é atribuir a responsabilidade de alguma coisa. Imputabilidade penal é conjunto de condições pessoais que dão ao agente capacidade para lhe ser juridicamente imputada a prática de um fato punível, e ainda, imputável é os sujeito mentalmente são e desenvolvido que possui capacidade de saber sua conduta contraria os mandamentos da ordem jurídica.

\section{CONCLUSÃO}

Falado sobre quem deve responder por seus atos, traremos para fins de pesquisa e compreensão, que algumas pessoas não poderão responder pelo delitos por eles cometidos, elemento conhecido como inimputabilidade, que por óbvio elenca as hipóteses de exclusão de imputabilidade. O legislador para tratar dos doentes mentais ou aqueles que não possui discernimento suficientes de compreender seus atos, arrola no artigo 26 do CP:

"Art. 26 - É isento de pena o agente que, por doença mental ou desenvolvimento mental incompleto ou retardado, era, ao tempo da ação ou da omissão, inteiramente incapaz de entender o caráter ilícito do fato ou de determinar-se de acordo com esse entendimento."

Podendo vir a ser divididos em:

a) O doente mental;

b) Aquele que tem desenvolvimento mental incompleto;

c) Aquele que possui desenvolvimento mental retardado.

Na legislação penal brasileira, não há um entendimento pacífico sobre o caminho a qual se deve dar a um psicopata, nesta toado é preciso mencionar que possui assim diferentes posições que leva a inimputabilidade, semi-imputabilidade e imputabilidade.

A jurisprudência, por meio de decisões monocráticas, vem se posicionando sobre a semiimputabilidade do psicopata, pois o mesmo não é considerado como doente mental, mesmo estando no CIDE (classificação internacional de doenças), ele não é visto como tal.

Mas, o que pode ser observado é o tema dos psicopatas não possui nada específico afim de solucionar perante a doutrina e judiciário e legislativo, fazendo que tais agentes (psicopatas) não tenham uma pena correta no seu plano existencial.

\section{REFERÊNCIAS}

CLECKLEY, Hervey. The Mask of Sanity: Na Attempt to Clarify Some Issues About the So-Called Psychopathic Personality 5th. Augusta, Georgia (s.N), 1988.

COSTA, Christian. Se o Mal Tivesse um Nome. Manaus: Valer, 2014.

HARE, Robert D. Sem consciência: o mundo perturbador dos psicopatas que vivem entre nós. Tradução de Denise Regina de Sales. Porto Alegre: Artmed, 2013.

JESUS, Damasio de. Direito Penal - Parte Geral 31 ed. São Paulo: Editora Saraiva, 2010.

MELIÁ, Manual Cancio. Psicopatía y Derecho penal:algumas concideraciones introductorias. In: CRESPO, Eduardo Demetrio (Org). Neurociencias y Derecho Penal - nuevas perspectivas em el ámbio de la culpabilidade y tratamento jurídico-penal de la peligrosidad. Madrid Edisofer, S.L; 2013. 
PRADO. Luiz Regis. Curso de Dlireito Penal brasileiro. Volume 1, parte geral 1. 7 ed. São Paulo: Editora Revista de Tribunais. 2007. 